MAX-PLANCK-INSTITUT FÜR WISSENSCHAFTSGESCHICHTE

Max Planck Institute for the History of Science

2013

PREPRINT 448

Jürgen Renn

Einstein as a Missionary of Science 



\title{
Einstein as a Missionary of Science ${ }^{1}$
}

\begin{abstract}
The paper reviews Einstein's engagement as a mediator and popularizer of science. It discusses the formative role of popular scientific literature for the young Einstein, showing that not only his broad scientific outlook but also his internationalist political views were shaped by these readings. Then, on the basis of recent detailed studies, Einstein's travels and their impact on the dissemination of relativity theory are examined. These activities as well as Einstein's own popular writings are interpreted in the context of his understanding of science as part of human culture.
\end{abstract}

\section{Introduction}

A widespread image of Einstein is that of the isolated genius brooding over ideas far removed from our everyday lives. Recent scholarship has changed this image and revealed the astonishing extent to which Einstein was also a man of this world. He was indeed a scientist who had collaborators and friends with whom he exchanged ideas. But he was also a politically engaged citizen who opposed militarism and nationalism, an unorthodox Jew and critical supporter of Zionism, and a man attracted to women he did not always treat as he should have. There is one aspect of his life and work, however, which has not yet received the attention it deserves: Einstein as a missionary of science, a popularizer, a communicator, an educator, and a moderator of science on the international stage.

This aspect has not only been neglected because it does not fit our image of Einstein as the isolated philosopher-scientist pondering the mysteries of the universe. The claim that Einstein dedicated himself in any significant way to the communication of science seems not to square with our ideas of science itself. Scientists solve problems; journalists and popular writers disseminate their findings. If great scientists such as Steven Hawking occasionally also act as popular science writers, the strict border between serious research and popular dissemination remains nevertheless unquestioned. No one would confuse $A$ Short History of Time, for instance, with Hawking's scientific publications.

Did Einstein actually dedicate significant efforts to disseminate science, to communicate his results to a broader public, to foster educational activities, and to build international networks of exchange? Or did he just occasionally enjoy fame in the media, for instance, when the results of the famous 1919 eclipse expedition confirmed the predictions of his general theory of relativity? In the following, I will argue that Einstein deliberately lent his name not only to political causes, but also to the public dissemination of scientific knowledge on a worldwide level. Both interests are closely associated with his personal

\footnotetext{
${ }^{1}$ This paper was presented at the 5th ESHS conference in Athens, November 4 2012. It will be published in Science \& Edutcation. The final publication is available at http://link.springer.com.
} 
experiences: from his early education to his politicization at the beginning of World War I. Like few other scientists, he succeeded in conveying the results of his work to a broader public. Einstein not only published popular works and newspaper articles on his relativity theories, but also held generally comprehensible lectures in publically accessible venues, such as adult education institutions and planetariums. In February-March 1920, for example, he gave a series of ten lectures on kinematics and equilibrium of bodies for the general public of the Adult Education College of Berlin (CPAE, vol, 9, p. 599). And in 1931 he famously lectured at the Marxist Workers' School on "What a Worker Needs to Know about the Theory of Relativity" (Fölsing 1997, p. 644).

I will now review some of Einstein's activities as a cosmopolitan missionary of science, roughly following his own biographic account (Einstein 1992). The breadth of these activities is so enormous as to merit a book-length account. This review can only offer glimpses into the lectures, travels, teachings, and correspondence he used to disseminate science. What will become clear from these glimpses, however, is the important role that public reflection on science played in Einstein's own intellectual development. His thinking was to a surprising degree a public activity; it was an open discourse not just with specialists, but also with the shared scientific knowledge of humanity, and an ongoing reflection on the very possibility of science. When Einstein talked with God, what he often meant was this shared background of science conceived as a quintessential human activity. For instance, can we as human beings proceed to rationally understand the world if it is governed simply by chance? This doubt is, I believe, what is behind Einstein's conviction that "God does not play dice." Einstein was a missionary of science and his message was that science is the only way we humans can ultimately cope with the challenges of this world. Let me begin with a discussion of some of the roots of this conviction in Einstein's biography.

\section{Einstein's Early Influences}

Einstein enjoyed support for his scientific interests from an early age, particularly from the medicine student Max Talmey, formerly Talmud, who boarded with the Einstein family by arrangement of the Jewish community in the late autumn of 1889. Max Talmey was the son a Rabbi born in Lithuania, which at that time was part of the Russian Empire. Here, many people lived together: Jews, Poles, Lithuanians, Russians, and Germans. He more than likely spoke Yiddish at home and German at school. Because of anti-Semitic discrimination, Talmey was unable to study at home, but had to emigrate to Bavaria, at that time not part of Germany. He later emigrated to the United States where he dedicated himself to the development of an international language similar to Esperanto (Ravin 1997). He was the key figure to influence Einstein's ideas about people and about humanity. In short, he was the intellectual father of "Einstein the intellectual."

\footnotetext{
${ }^{2}$ Letter to Max Born 4 December 1926 in (Einstein and Born 1969, p. 27).
} 


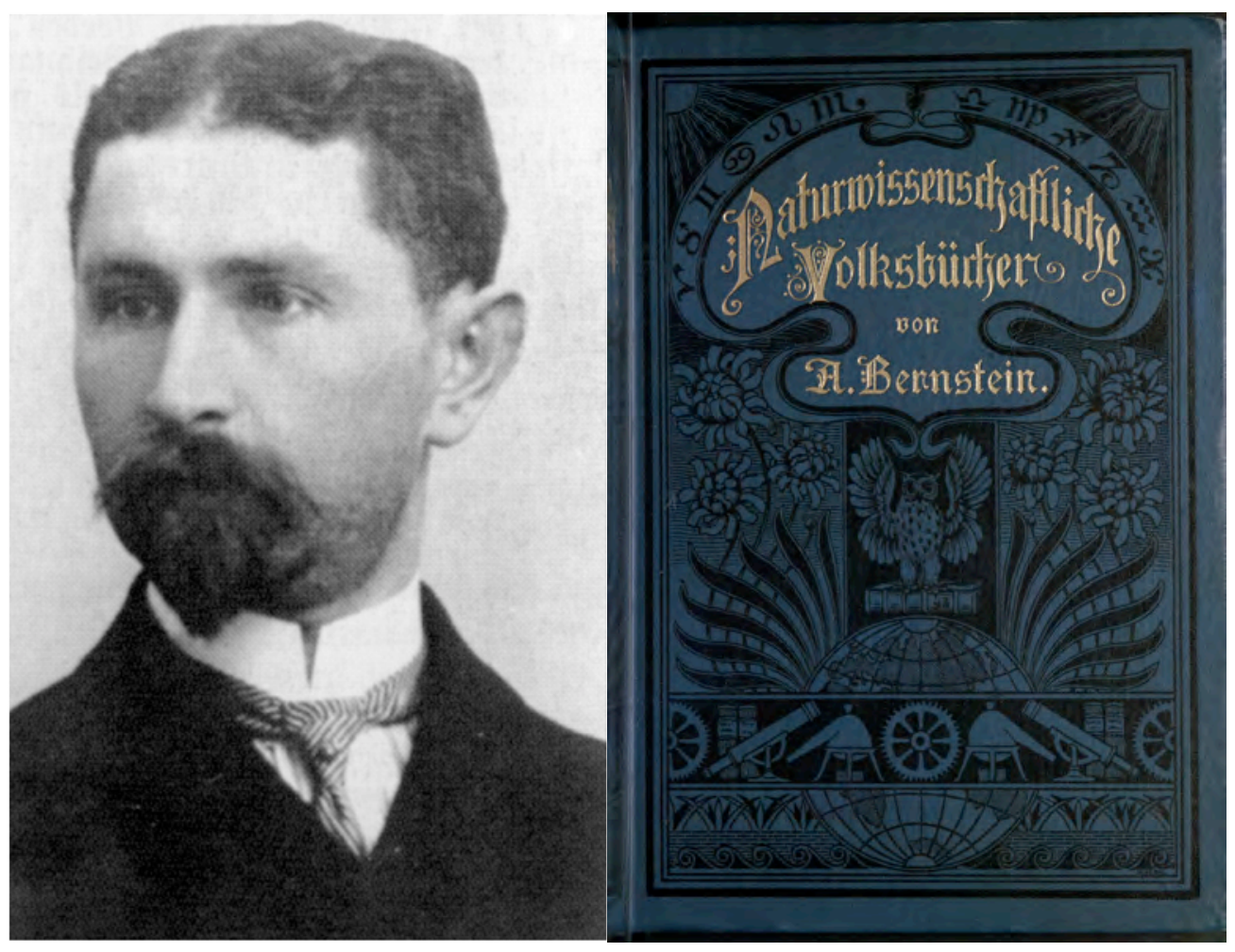

Figure 1: Max Talmud (1869-1941), one of Einstein's earliest mentors.

Figure 2: Aaron Bernstein's popular scientific books (1867-1869).

One of Talmey's special recommendations was to read Aaron Bernstein's popular books on natural science. Bernstein (1812-1884) was a Jewish theologian, author, and politician from Danzig who established a reputation as a popularizer of science (Gregory 1977). He had been a supporter of the failed 1848 democratic uprising and now hoped to promulgate the ideals of progress and democracy through the popularization of science. His books offer their readers a fascinating and even encyclopedic overview of the state of contemporary natural science.

These readings gave Einstein a singularly broad knowledge that rescued him from the narrow views of specialists and also familiarized him with the international spirit of science, including its philosophical and political implications. Reading Bernstein, who always emphasized the as yet unsolved scientific puzzles, helped to direct the boy's attention to those problems that later led to some of his revolutionary papers. These books were so much more than light reading or an introductory science course. They actually provided young Einstein with an overview of knowledge that made him see connections between separate fields of science that were overlooked or neglected by the specialists. From such books Einstein derived, for instance, the ambition to look for evidence for the real existence of atoms, which up to then had merely served as a working hypothesis. Indeed the reality of atomism was established not by a single discovery, but by integrating diverse strands of knowledge from chemistry, physical chemistry, optics, the theory of 
liquids, and many other fields. Books like the Volksbücher depicted such challenges as promising riddles that might be solved by an avid young reader. They may also have implanted in Einstein the political skepticism and freethinking that was his hallmark, also with regard to the German Kleinstaaterei (regional pettiness) that is still present in today's German Federalism. In one of his books, for instance, Bernstein wondered how some German lands such as Hessen might appear if observed from the moon and whether what was going on there would at all be visible, even with a telescope (Bernstein 1897, vol. 3 , part 16, p. 57).

Behind the numerous ideas and speculations that Einstein developed during his student days and that he discussed with his friends was a fascination with the notion that one can discover a unity in natural phenomena by going beyond the direct sensual experience. ${ }^{3}$ This fascination was also rooted in his earlier readings of popular scientific books. At the age of 67, Einstein still remembered this incisive educational experience:

When I was a fairly precocious young man I became thoroughly impressed with the futility of the hopes and strivings that chase most men restlessly through life. As the first way out there was religion, which is implanted into every child by way of the traditional educationmachine. Thus I came - though the child of entirely irreligious (Jewish) parents - to a deep religiousness, which, however, reached an abrupt end at the age of twelve. Through the reading of popular scientific books I soon reached the conviction that much in the stories of the Bible could not be true. The consequence was a positively fanatic [orgy of] freethinking coupled with the impression that youth is intentionally being deceived by the state through lies; it was a crushing impression. Mistrust of every kind of authority grew out of this experience, a skeptical attitude toward the convictions that were alive in any specific social environment - an attitude that has never again left me, even though, later on, it has been tempered by a better insight into the causal connections. (Einstein 1992, 3, 5)

As is well known, as a youth Einstein spent some time with his family in Italy escaping the rigid German school system. ${ }^{4}$ This was for him another cosmopolitan experience as it familiarized him with a different human, cultural, and social environment. He simply learned that things could also be done differently. The same holds for his student days in Switzerland, where he was confronted with students from all over Europe. Einstein's closest friends came from Rumania (Solovine), Serbia (his later wife Mileva), and from Trieste (his close friend Michele Besso). He was thus exposed to a truly cosmopolitan experience that his early readings helped put into a larger perspective.

Through these readings, science for the young Einstein became an orientation in life; it replaced religion with the promise that with its help, one could rise above the void of earthly hopes and ambitions. Bernstein's popular books in particular opened up science as a human enterprise, not only to be admired, but also one to participate in. In contrast to contemporary compartmentalized academia, Bernstein drew no sharp boundaries, neither

\footnotetext{
${ }^{3}$ Einstein to Marcel Grossmann, (CPAE, vol. 1, pp. 290-291).

${ }^{4}$ See (Einstein 1987-2009; Fölsing 1997; Franck 1953; Isaacson 2007; Neffe 2005; Renn 2005a, 2005b, 2006; Seelig 1956).
} 
between the sciences nor between science and life. His transcendence of boundaries did not simply offer orientation in the world of science, he also used the breadth of the scientific view to point to the narrowness of political relations. Bernstein thus rounds off the description of a cosmic journey with a somewhat melancholic reflection on the meaning of a life that centers on education and science:

With such mixed feelings there is nothing left for us but to part in serene solemnity with the wonders of the universe. This serene solemnity is equally remote from arrogant pride and oppressive humility. It comforts and soothes us through its call to fulfill the mission of our existence in the earnest nurture of our spirit. And when we complete this daily work we part from this existence joyous in the knowledge that we have lived for future generations of searchers. (Bernstein 1897, vol. 3, part 16, p. 209)

The overview of the natural sciences of Einstein's time, gathered from Bernstein's books, was linked with the hope of achieving a conceptual unity of their numerous specialized branches. Having such reading material as a starting point, Einstein developed a different view of physics than most of his established physicist colleagues, who sometimes lacked vision of the overarching connections between the special topics they were investigating.

\section{Einstein, Besso, and the Olympia Academy ${ }^{5}$}

The scientific worldview of young Einstein would not have been as productive had it relied exclusively on individual imagination, that is, lacking the influence of a community. During his student days in Zurich and the early years at the patent office, Einstein was in fact surrounded by friends with whom he could discuss the foundational questions of science without having to respect disciplinary boundaries or the authority of established schools. In this society of rebels, which had much in common with the Bohemian society of artists of that time, scientific questions became questions about life itself. In addition to his girlfriend and later spouse Mileva, his most important partners included Michele Besso, a rather unsuccessful engineer but Einstein's favorite sounding board. In Einstein's 1905 paper on relativity, Besso was the only person to receive acknowledgement, as Einstein later recalled because the decisive idea came to him in conversation with his friend. Together with this circle of friends Einstein cultivated a critical reflection on established science.

\footnotetext{
${ }^{5}$ This section is based on (Renn 2005a, 84-89).
} 


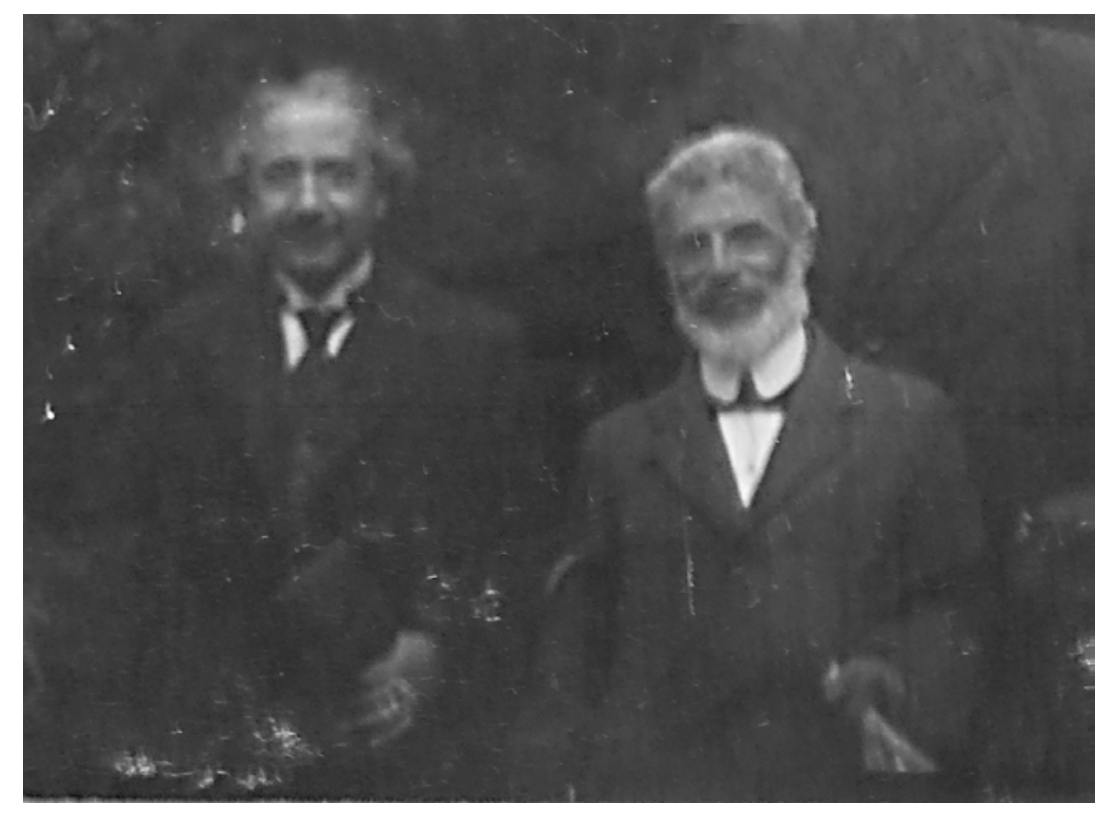

Figure 3: Einstein with Michele Besso, his lifelong friend.

The rebellion against topical science, considered overspecialized and misguided by an overreliance on authority, was paired with contempt of middle-class morality. Einstein's correspondence from those years provides eloquent evidence of this attitude, and more so the founding in 1902 of the utopian "Olympia Academy" together with Conrad Habicht and Maurice Solovine. Throughout his life, he would continue to favor this academy over the official ones. Here, he was ironically worshiped as antistes infallibilis ecclesiae pauperorum spiritu, that is, "infallible master of the church of spiritual paupers." As president of the academy, he bore the honorary title "Albertus knight of the tailbone."

The preferred readings at the sociable meetings of the Olympia Academy were works in which conceptual and methodic questions of contemporary science were critically reviewed. These included books by Ernst Mach and Henri Poincaré, the philosophers Baruch de Spinoza and David Hume, and writers such as Miguel de Cervantes and Charles Dickens. So this academy and its circles were by no means a sophomoric jest, but a collective of thinkers. Einstein continued to draw on its strengths even as a famous scientist, albeit one disappointed more than once by the lack of open-mindedness of his professional academic colleagues.

The correspondence from the last two years before his annus mirabilis 1905 documents just how important his discussion partners must have been to him. He awaited each session of the alternative academy impatiently, as he formulated in a November 1903 letter to Habicht:

Two orphaned membra are sitting here and dreaming of an extraordinary meeting. (Agenda of no importance) So, up, you lazy member! (CPAE 5E, 15) 
A letter from spring 1904 sounds quite similar:

I will receive you with pleasure and with the rest of my feelings-we have put that in preserve jars for appropriate occasions - and in a cheerful mood as well at Kramgasse 49, II floor. Solovine is not yet within hearing distance, but he is bound to come soon. Do come at once, you have a bike, after all! [...] Waiting impatiently for the world's laziest letter-writer, yours truly, A.E. (CPAE 5E, 16f.)

The decisive breakthrough in the year 1905 was likewise announced in a letter from Einstein to one of his early companions, Conrad Habicht, cited above. The letter begins in a mocking tone, before concluding with the momentous announcements of his scientific breakthroughs.

Such a solemn air of silence has descended between us that I almost feel as if I am committing a sacrilege when I break it now with some inconsequential babble. But is this not always the fate of the exalted ones of this world?

So, what are you up to, you frozen whale, you smoked, dried, canned piece of soul, or whatever else I would like to hurl at your head, filled as I am with $70 \%$ anger and $30 \%$ pity! You have only the latter $30 \%$ to thank for my not having sent you a can full of minced onions and garlic after you so cravenly did not show up on Easter. But why have you still not sent me your dissertation? Don't you know that I am one of the $11 / 2$ fellows who would read it with interest and pleasure, you wretched man? I promise you four papers in return [...]. (CPAE 5E, 19f.)

As is well known, the beginnings of his scientific career were difficult. He had to struggle to get his Ph.D., and at first had to work at the Swiss Patent Office as he was unable at first to secure an academic position (Schulmann 2005). One may imagine that at the time he had other things to do besides acting as a missionary of science. Yet he did, in particular, in the context of the private associations for natural history that were customary at the time in Switzerland and in Germany. What was their historical background? In the second half of the nineteenth century, the development of science and technology and their growing significance for everyday life were linked with hopes for extensive social progress. In Germany, after the revolution of 1848, a newly self-confident middle class demanded increasing participation in all aspects of public affairs, including science and technology.

Against this background, many scientists felt it their duty not just to communicate among themselves, but also to make their knowledge accessible to the wider public. The natural history societies become meeting places in many towns for both scholars and laypeople interested in science. The members of these societies discussed scientific matters in a convivial atmosphere and went on nature study walks together. Einstein joined the Natural History Society of Bern in 1903 and regularly attended its evening meetings at the Storchen Inn, together with a colleague from the patent office. That same year he gave his very first lecture on The Theory of Electromagnetic Waves. Even after becoming a famous scientist, Einstein continued to attend meetings of Swiss Natural History Societies. 


\section{Einstein's Early Career ${ }^{6}$}

Einstein was invited to lecture on a more professional level after becoming an associate professor in Bern in 1908 and after receiving his first academic appointment at the University of Zurich in 1909. The number of trips he undertook and the variety of themes he dealt with in his talks is impressive. They testify to the high mobility of young researchers and to the density of the European network of science in the period shortly before World War I. In February 1909, Einstein lectured in Zurich on electrodynamics and relativity theory. In September 1909, he gave a famous lecture on the state of the radiation problem in Salzburg. In May 1910, he presented a talk to the Swiss Physical Society in Neuchatel on light quanta and electromagnetic energy. In September, he talked in Basel about magnetism, and in November in Zurich about Boltzmann's principle. In February 1911, Einstein talked in Leiden about Brownian motion, and in April of the same year he visited Sommerfeld and Debye in Munich to discuss the generalization of relativity theory and other themes.

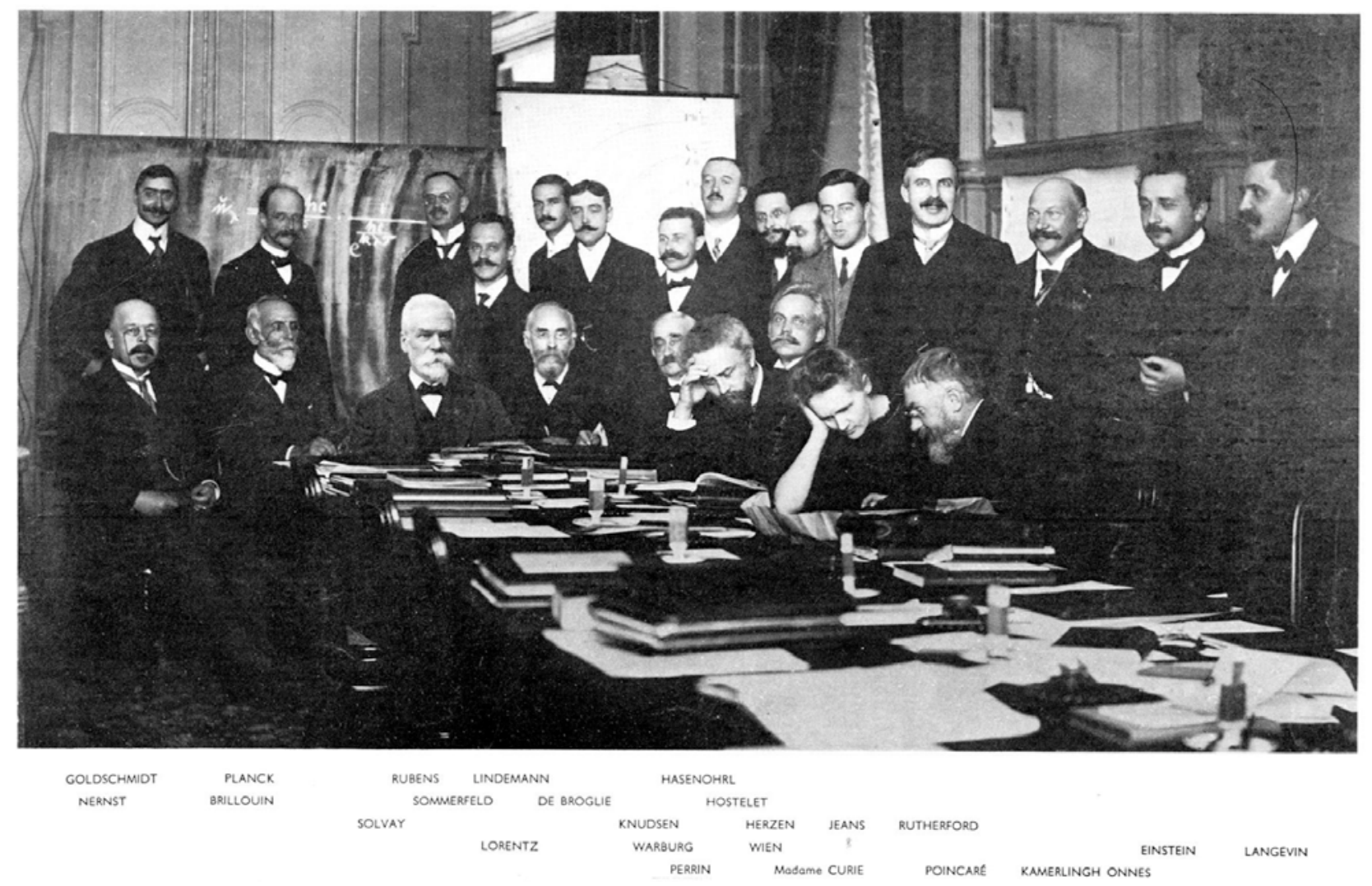

Figure 4: Participants at the first Solvay Conference in 1911.

\footnotetext{
${ }^{6}$ See (Einstein 1993, 1995). See also the "Chronology" in (Einstein 1995, p.617 ff.).
} 
In April 1911, Einstein moved to Prague where he immediately gave several talks, including one about the influence of gravity on the propagation of light in the hope of attracting the interest of astronomers to his new theory of gravitation (Buchwald et al. 2013; Renn 2005d). In September of that year, he discussed quantum theory, electrical and thermal conduction, and infrared absorption in gases at the Karlsruhe meeting of the German Society of Natural Scientists and Physicians. In October, he gave several lectures on the progress of physics in Zurich. In November 1911, Einstein attended the first Solvay meeting in Brussels, lecturing on specific heats and participating in the wide-ranging discussions there. In April 1912, he visited Nernst, Haber, Warburg, Rubens and Freundlich in Berlin, discussing heat radiation, photochemistry, low temperature physics, and gravitational lensing (Renn et al. 1997).

One should not forget that, during the time covered so far, roughly from beginning of 1909 to the spring of 1912, Einstein had to deal with a full teaching load that included courses on thermodynamics, kinetic theory, radiation theory, and mechanics. And one should not forget all the scientific contributions Einstein made during this time. These ranged from the first analysis of critical opalescence, his ongoing work on radiation and quantum theory, to the monumental discovery of the metric tensor as the mathematical representation of the gravitational potential, a discovery that opened the route to general relativity. While in Prague, Einstein also participated in the so-called Fanta circle where scientific, philosophical, and literary issues were discussed. Here he met, for example, Max Brod, a friend of Franz Kafka who later portrayed Einstein in his novel about Kepler.

When Einstein moved back to Zurich later in 1912, his relationships with his student friends Marcel Grossmann and Michele Besso played an important role in his elaboration of the general theory of relativity, although neither Grossmann nor Besso were by any means experts in the physics involved. This collaboration was all the more important since his professional colleagues remained skeptical with regard to the newly emerging theory of gravitation, even after Einstein's call to the prestigious position at the Berlin academy in 1914.

To summarize, we have so far seen how Einstein himself benefitted from other missionaries of science, being stimulated to become a scientist by popular scientific readings and encouraged to develop unconventional views by a community that extended beyond the specialist boundaries of science. We have seen that he remained faithful throughout his life to this broad and philosophically inspired science tradition that was shaped by a belief in social progress through science and technology. We have also seen how, as a young scientist, Einstein became a member of the central European network of science, benefitting from it with his wide-ranging scientific interests and contributing to the sharing and dissemination of a non-specialist outlook on science. 


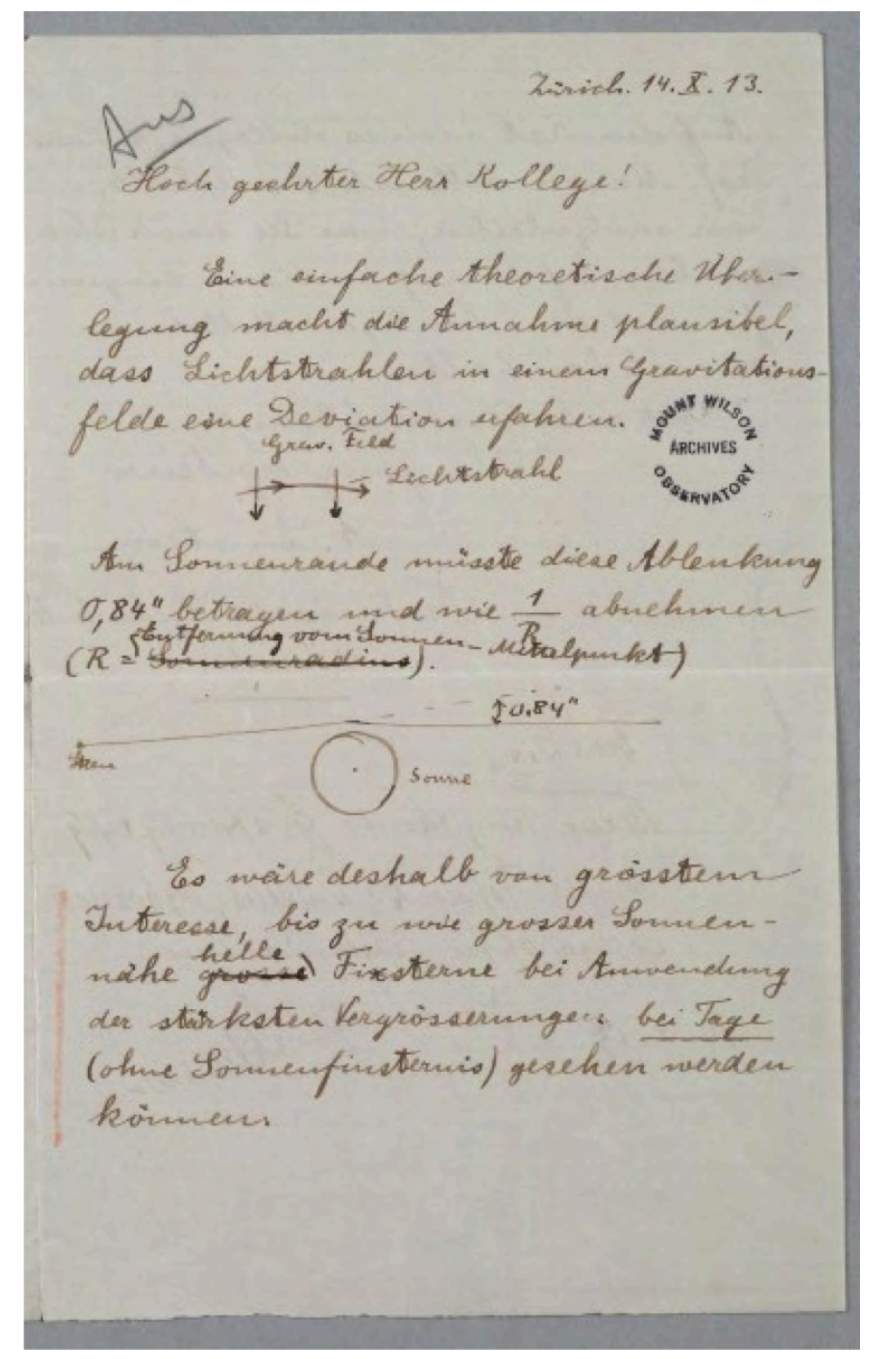

Figure 5: Einstein's letter to G. E. Hale in 1913.

After 1912, on the verge of creating general relativity, Einstein became a missionary of science in yet another sense. General relativity created a new bridge between physics and astronomy; it was inspired by fundamental conceptual challenges of physics and had farreaching astronomical consequences. In order to validate its predictions, it was therefore necessary to involve astronomers and to engage in a new form of collaboration between physics and astronomy. Ultimately, it was the challenge to create and further develop an astrophysical community that until then was practically non-existent. As mentioned earlier, Einstein made great efforts to motivate astronomers such as G.E. Hale to check his predictions of general relativity, such as the gravitational bending of light and gravitational red-shift (Figure 5). But his attempts met with indifference and even resistance. Only gradually did he succeed in rousing the interest of astronomers who, at the time, were more interested in precision measurements and other more specialist concerns (Renn et al. 1999). 


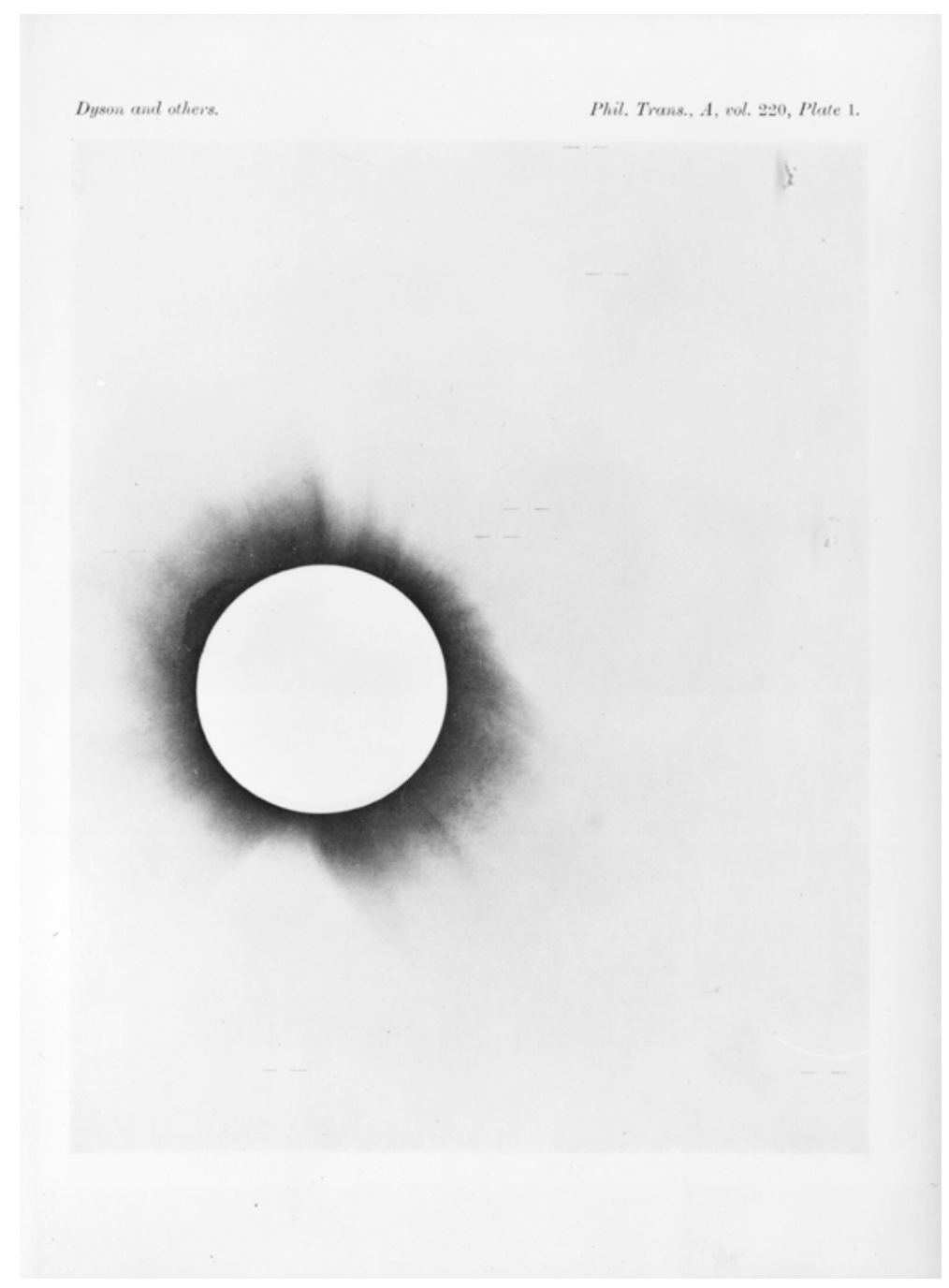

Figure 6: Image of the total solar eclipse of 1919 in Philosophical Transactions A, vol. 220, London, June 1920, Plate I.

As is well known, the turning point came in 1919 when the English eclipse expedition led by Sir Arthur Eddington confirmed Einstein's prediction of the gravitational bending of light. Thus, not long after the First World War, an English expedition had contributed to the success of the theory of a German-Swiss Jewish scientist. In this way, science became a messenger of international cooperation and Einstein its leading protagonist. Einstein became a media celebrity practically overnight and proved well prepared to make judicious use of this prominence. From an early age, his thinking had been framed in internationalist and anti-militarist terms and, as I have stressed, he felt that science should not be pursued as a narrow-minded, specialist enterprise. Einstein therefore took up the challenge of addressing the then still fledgling mass media and tried to explain aspects of his revolutionary theory to a wider public. 


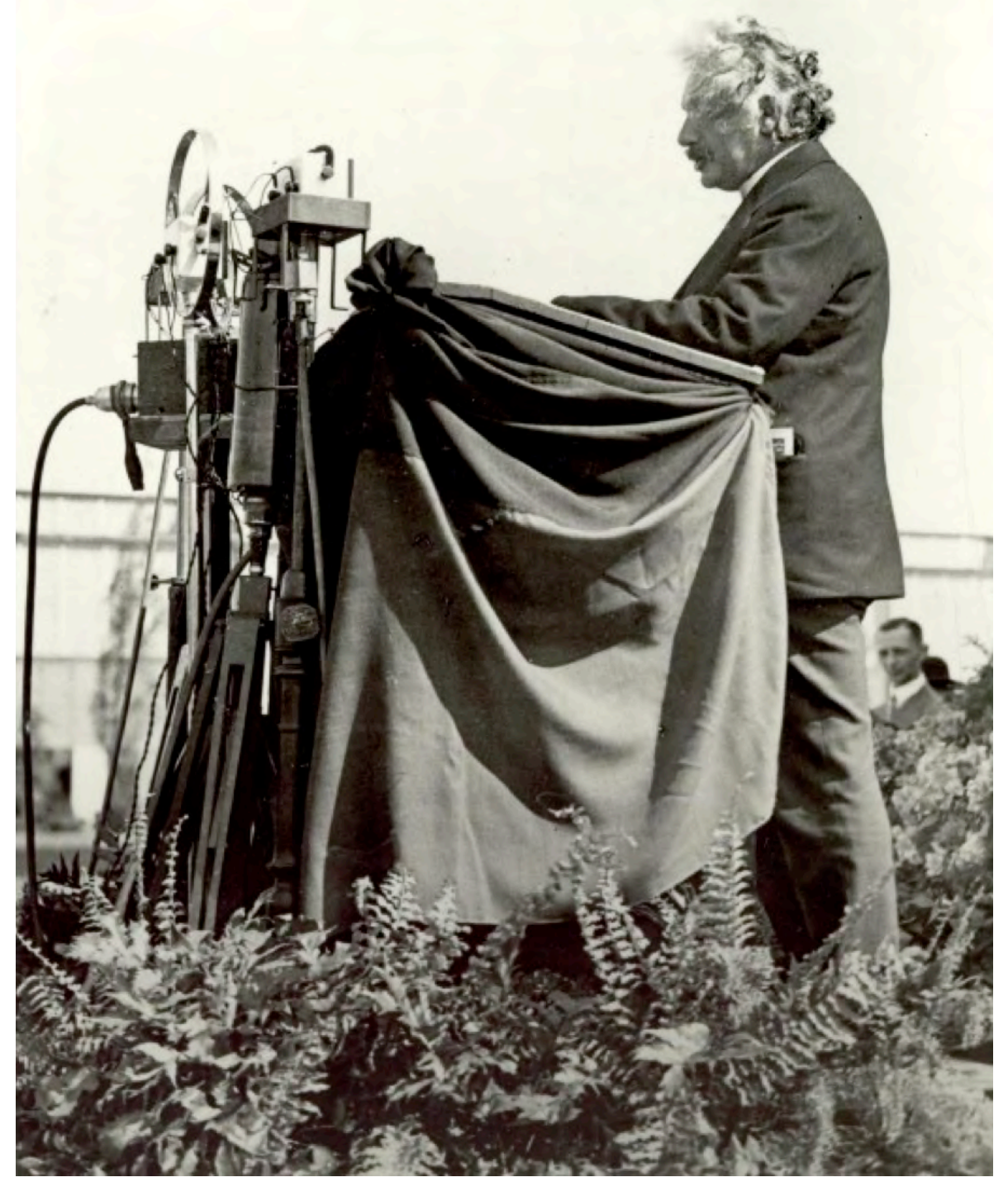

Fig.7: Einstein opening the 1930 Funkausstellung (German Radio and Phonograph Exhibition) in Berlin.

Without the modern mass media, Einstein would never have become as famous as he did following the verification of the theory of relativity in 1919. Thousands of articles and other items appear within a brief period, from popular introductions to Einstein's theory to satires and even a waltz named "According to the Principles of the Theory of Relativity" (Renn 2005a, 122-125; Wazeck 2005, 2009). In 1930, Einstein opened the famous Radio and Phonograph Exhibition in Berlin. He expressed his conviction that radio would act as an instrument of social progress. Not long afterwards, moreover, his hope was bitterly dashed by the manipulative use of mass media during National Socialist rule. 


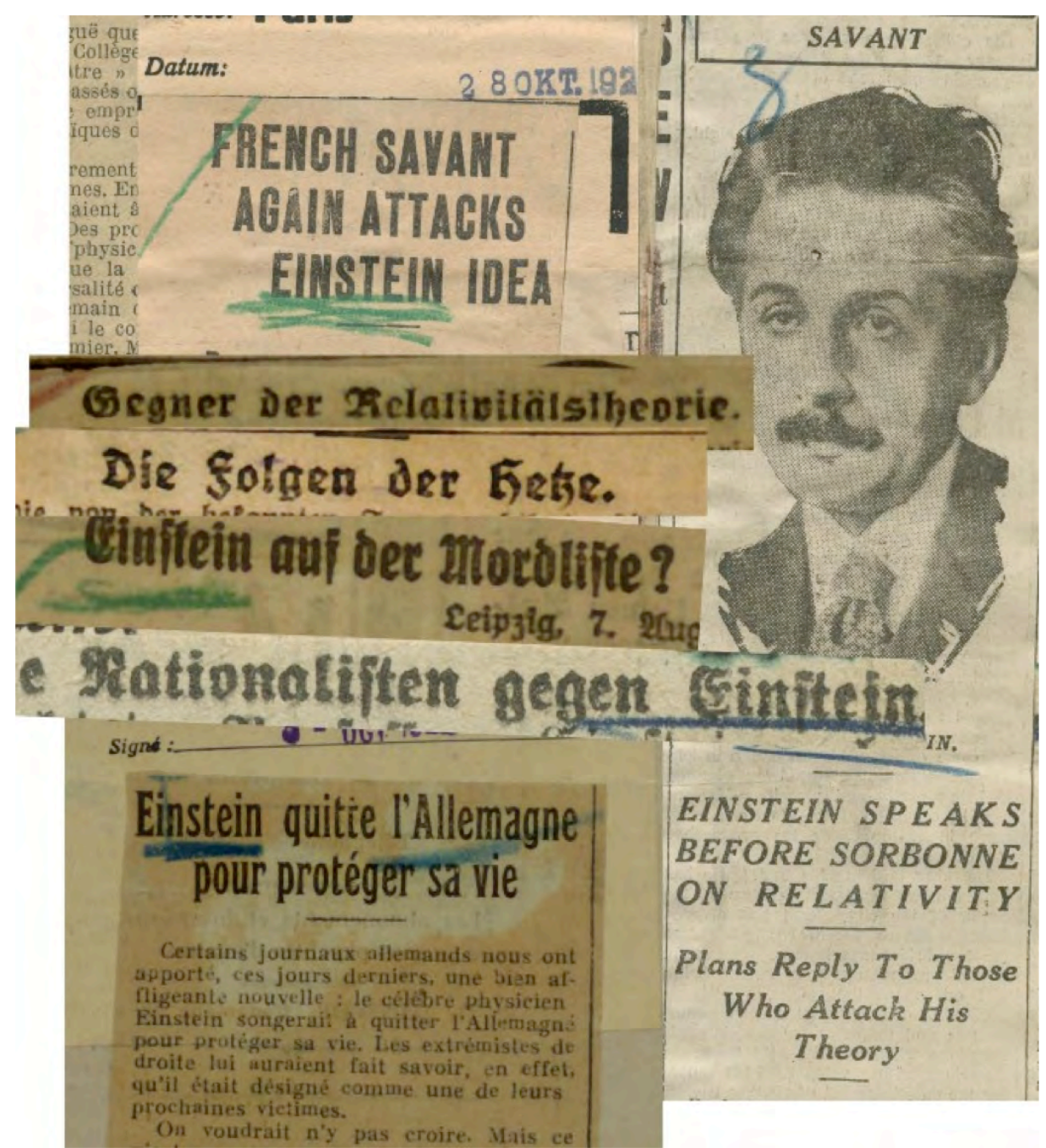

Figure 8: Photo montage of clippings from the anti-rationalist, anti-semitic and nationalist press against Einstein, around 1920.

Returning to the period shortly after 1919, Einstein was of course not the only one to seize the opportunity of the spectacular scientific success marked by the eclipse expedition. The years after 1919 witnessed a wave of popular accounts of relativity and soon after, also the rise of an anti-relativity movement (Wazeck 2009). In the postwar period, relativity theory became a public issue loaded with anti-rationalistic, anti-Semitic and nationalistic resentments on the one hand, and interpreted as a symbol of international cooperation and a new worldview on the other. There was, however, a remarkable disparity between the public and the professional reception and impact of general relativity. Since the mid1920s, professional physics was ever more dominated by the emerging quantum mechanics, while general relativity gradually disappeared into a specialist niche from which it only re-emerged after the Second World War (Eisenstaedt 1989). Even the discovery of evidence in favor of an expanding universe around 1930 and hence of the profound cosmological implications of general relativity did not advance this theory to the mainstream of modern physics. 


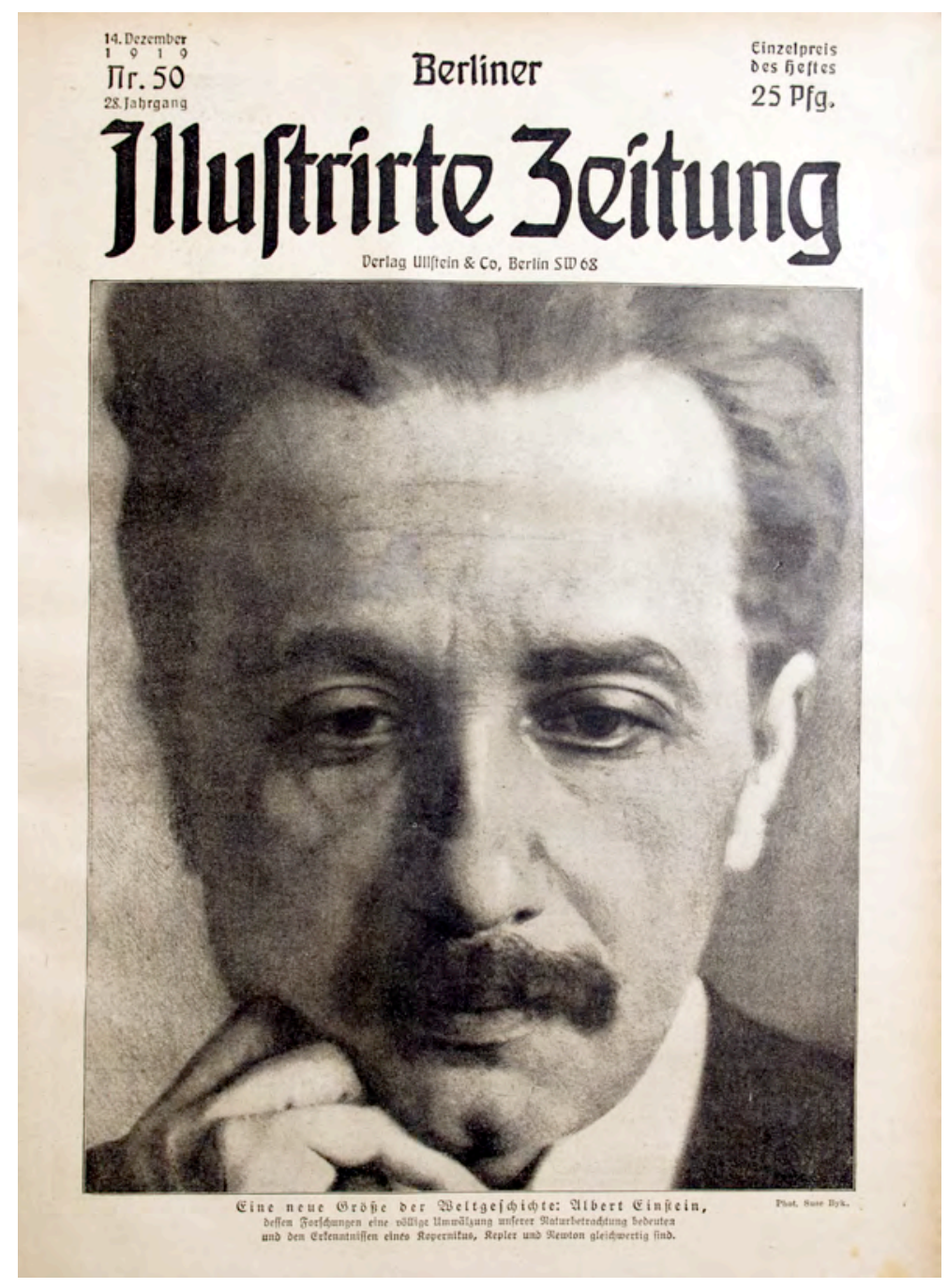

Figure 9: Einstein billed as "a new giant in world history" on the cover page of the Berliner Illustrierte Zeitung, December 14, 1919.

It is no exaggeration, on the other hand, to claim that the public reception of general relativity and its creator Einstein contributed to a change in the societal status of modern physics on a global scale. In the European centers and in the United States, first quantum and later nuclear physics became the most important driving force to enhance the societal relevance of physics due to their impact on a wide array of scientific fields and their actual and potential applications. At the European periphery and outside Europe and the United States, however, it was also the symbolic capital of Einstein's relativity revolution that helped to establish physics as a leading science of modernization, demonstrating that societal progress had become dependent on the progress of basic and not just applied science. 


\section{Einstein on the Road}

Einstein's personal contribution to this shift in perspective - as a cosmopolitan missionary of science during his trips in Europe, the United States, Asia, and Latin America-cannot be overestimated. He seems to have conferred some of the momentum of his youth from popular scientific culture to now couple scientific and societal progress on a global scale. In the following, let me therefore review some of these trips from this perspective, showing how they enhanced the processes of emancipation already underway in local scientific communities that were seeking a greater role for basic science in their societies. Of course, the local situations differed widely, from Spain to Japan, from Cleveland to Buenos Aires. A common feature of all the interactions between Einstein and the various scientific communities during his trips, however, was the significant increase in the awareness that basic science is a global endeavor of crucial relevance to all societies.

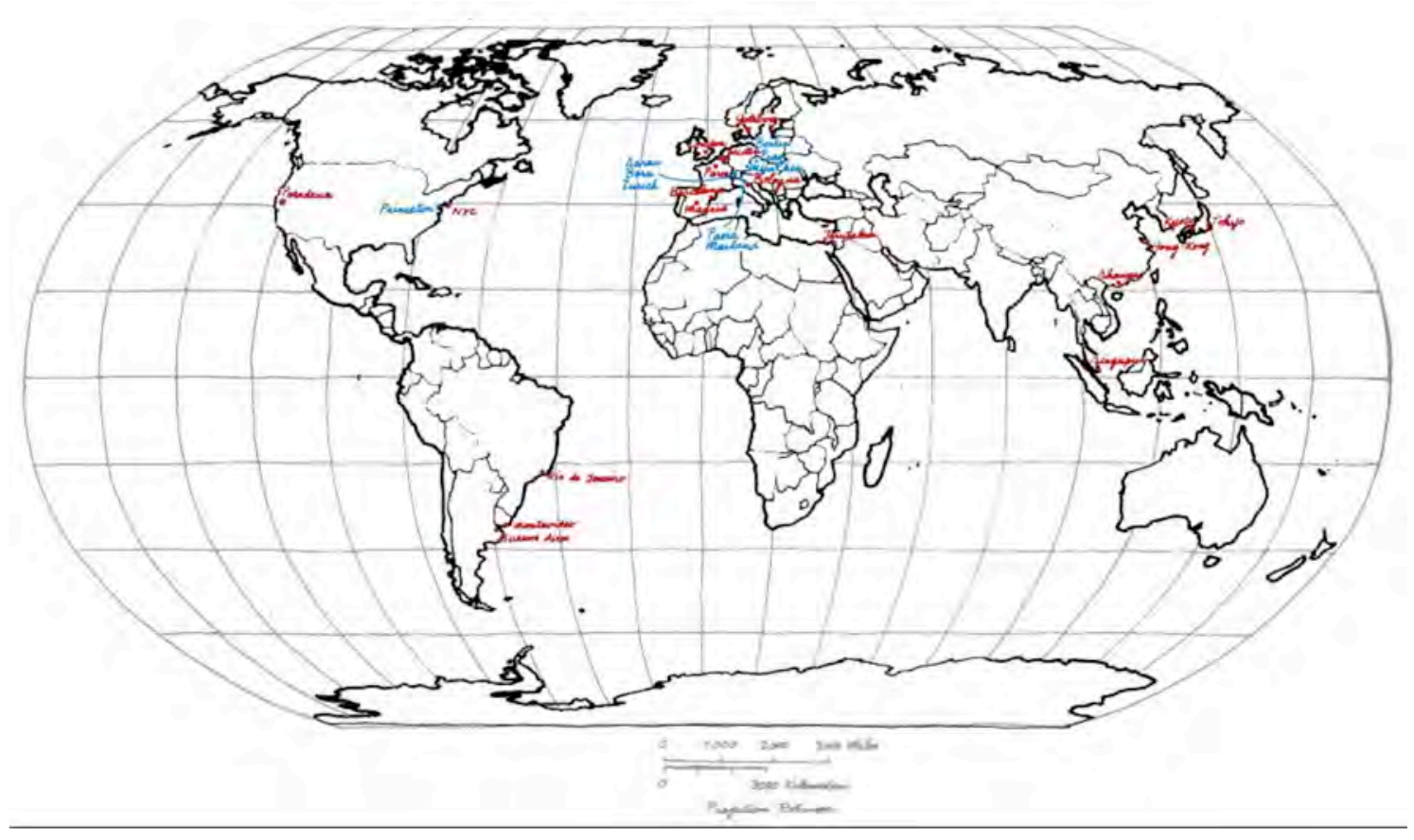

Figure 10: A map showing where Einstein lived (blue) and where he traveled (red).

After World War I, Einstein traveled to Prague, Vienna, Leiden, Oslo, and Copenhagen. The Ministry for Foreign Affairs considered him a "first-rate cultural factor" and hoped he would help to re-establish international ties. In 1921, he accompanied Chaim Weizmann on a fundraising tour through the United States. On the way home, he visited England where he overcame the initial frosty reception with a lecture on the international nature of science. In October 1921, he gave talks in Bologna and in Padua on special relativity and on general relativity and its cosmological consequences (CPAE, vol. 12, p. 476-477). At 
Walter Rathenau's request, Einstein accepted an invitation to Paris. In 1922, he was the first German scientist to be received in France after the war. Following Rathenau's murder and his own death threats, Einstein's journey to Japan in the autumn of 1922 provided a welcome escape from Germany. On his return journey at the beginning of 1923, he visited Palestine and Spain. His next major journey abroad in 1925 took him to South America. On this trip, he once again inspired scientific life: he supported the founding of the Hebrew University in Jerusalem by collecting donations, he encouraged Jewish communities, and also strengthened the reputation of the fledgling German democracy.

\section{Einstein in Japan}

Einstein's 1921 visit to America was the beginning of the unwavering Einstein myth in popular American culture. His 1922 visit to France was a turning point in the tense French-German scientific relations, but failed to convince the majority of French scientists of relativity theory. During his trip to Japan in 1922 and 1923, Einstein was awarded the Nobel Prize for physics. Also in Japan, he was a greeted as a public figure symbolizing both the role of science in modern society and the spirit of international cooperation associated with it (Sugimoto 2005). In a cabinet meeting, ministers even debated on whether or not the theory of relativity was comprehensible. According to the Minister of Education, ordinary people were able to understand the theory. The Minister of Agriculture objected to this, claiming that they could only vaguely understand it. The Minister of Justice, in contrast, was of the opinion that there is no middle ground between understanding and not understanding. After his trip, an edition of Einstein's works appeared in Japanese which became a reference point for Japanese science.

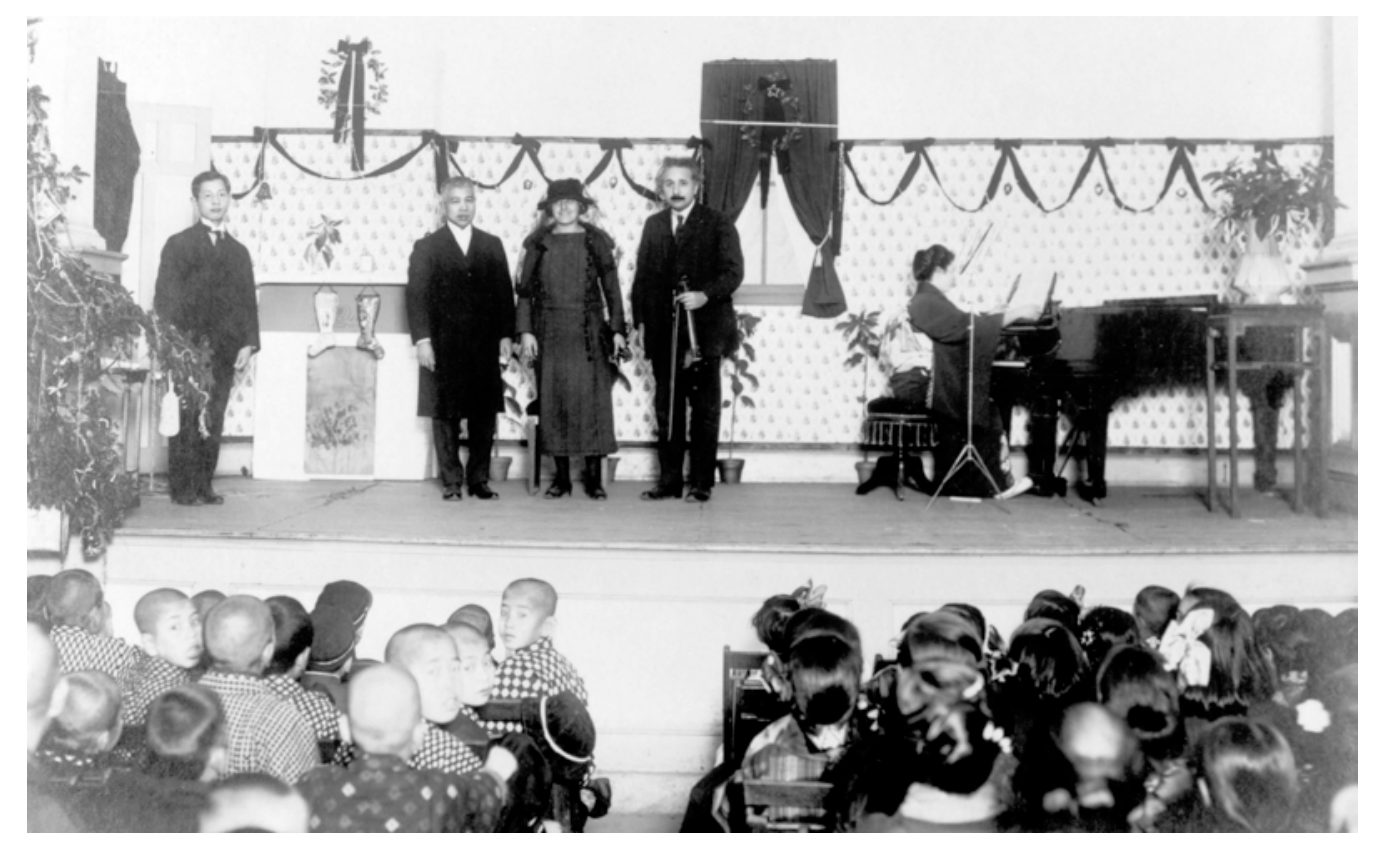

Figure 11: Einstein in Japan. 


\section{Einstein in Spain}

On his return from Japan at the beginning of 1923, Einstein visited Spain. He first gave a lecture in Barcelona and then went on to Madrid where he gave talks at the university, the Royal Academy, the mathematical society, and at the Technical University. His trip was concluded by two lectures in Zaragoza. The historian Thomas Glick has masterfully studied Einstein's visit to Spain. One of his central claims, which referred to the Spanish situation but is more generally valid, is that the symbolically charged reception of relativity "obliged scientists to confront both themselves and their disciplines" (Glick 1988). As a consequence, the advent of relativity and the public prominence of its creator triggered reflections about the status of science and of particular disciplines in a national community, as well as about the relation between local and global traditions of science. This was true for Einstein's visit to the United States and the reaction of American astronomers to the challenges posed by general relativity. It was equally true for the Spanish mathematicians who played an important role in the Spanish reception of the theory.

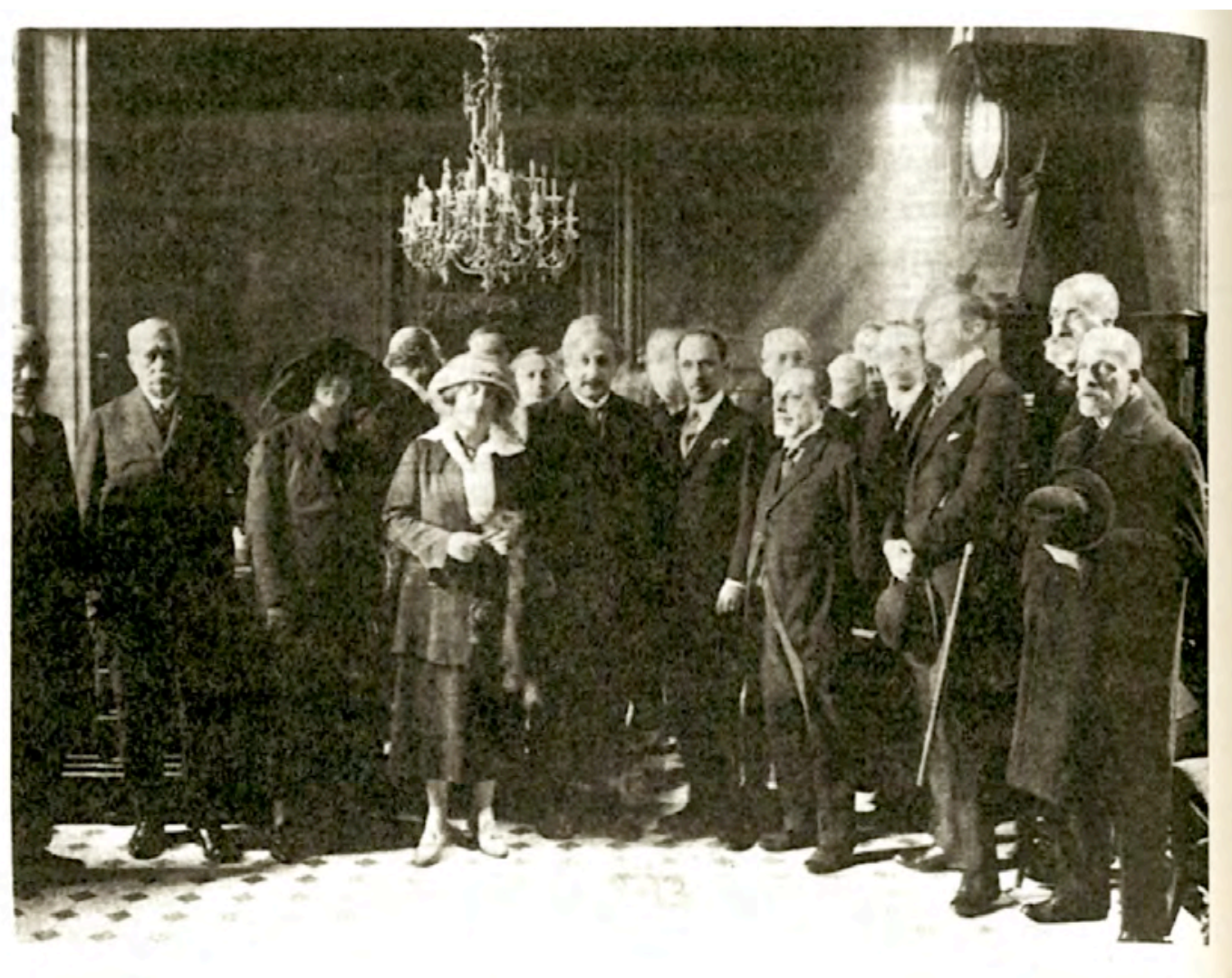

Figure 12: Einstein attends a reception at the City Hall of Barcelona. 
Referring to the Spanish reception of relativity, Glick has shown there was an eagerness of the scientific middle class and, in particular, of engineers to enhance their social status by fostering the societal recognition of science as a conduit of modernization (Glick 1988, $188 \mathrm{ff}$.). Yet, at the time, Spain was a country at Europe's scientific periphery. It was, however, on the brink of participating more intensely in the European science network. Spanish scientists such as Esteve Terradas had been living and working abroad, and foreign scientists such as Levi-Civita, Hadamard, Weyl and Sommerfeld had been lecturing or researching in Spain. It is against this background that Einstein's visit was able to make such a difference, enhancing a more global perspective on science and assessing Spain's position and role with regard to global science. Language skills also played an important role for exploiting opportunities to internationalize Spanish science. Blas Cabrera and Esteve Terradas, whose idea it was to invite Einstein, were able to discuss relativity with Einstein in German.

There were also remarkable differences in the reception of Einstein's lectures in Barcelona, Madrid, and Zaragoza. Einstein's new theory constituted an intellectual challenge everywhere. It was difficult both for Einstein and for his audience to cope with this challenge without making use of mathematical instruments that were not at everyone's disposal. And even if such instruments had been available, relativity theory presented enough conceptual novelties to confuse even an expert audience. In this situation, according to Glick, the Catalan reception was marked by an emphasis on the concrete observational evidence supporting the theory. While in Barcelona, Einstein also spoke at the anarchist syndical confederation, the CNT. It is uncertain whether he used the occasion to express sympathy for the revolutionary cause, but it has been established beyond doubt that Einstein recommended the workers read Spinoza as a "source of many good ideas and timely advice." The conservative Catalan nationalists also tried to benefit from Einstein's visit. One newspaper wrote: "In Barcelona the theory of relativity has served us for political ends, and we present Einstein as a perfect regionalist, as a kind of Cambó of mathematics" (Glick 1988, 114).

Einstein's visit to Madrid also provoked political reactions, but of a somewhat different kind. It implicitly raised the question of the status of Spanish science and seemed to offer an occasion to enhance this status by connecting it with Einstein. Einstein was even offered an official position as head of a joint Spanish-Mexican scientific commission to study the solar eclipse of 1923, an offer, however, that he declined. 


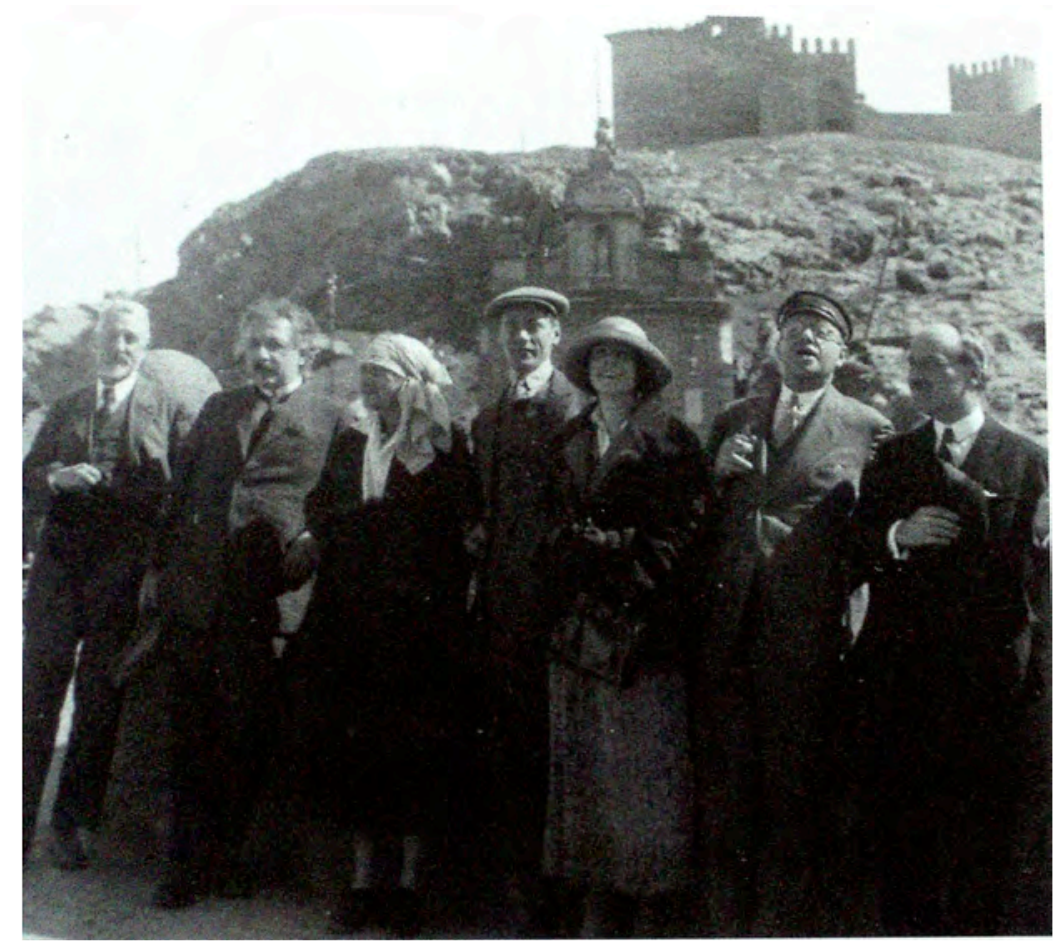

Figure 13: Einstein with Ortega in Toledo, March 1923.

On March 9, 1923, Einstein, accompanied by Ortega y Gasset, was invited to receive a public tribute at the Residencia de Estudiantes. In contrast to many other Spanish observers, Ortega stressed the empirical character of relativity theory and not its mathematical aspects. He approached Einstein's achievement from a historical point of view and characterized it as the seed of a new culture and the symbol of a new age. He found that Einstein's breakthrough was rooted in a new kind of experience. To Ortega, Einstein was a "breath of fresh air"; he had humanized physics. Ortega evidently saw a connection between his own concept of "perspectivism" and Einstein's theory. Just as perspectivism emphasizes that the order and the form that reality takes for a person depends on the place and may change when the place changes, properties such as length and time vary, according to the theory of relativity, in dependence on the system of reference (Glick 1988, 163).

But while his Spanish hosts, from the Catalan anarchists to Ortega, stressed the revolutionary and novel character of Einstein's science, Einstein himself in his reply to Ortega's speech, struck a different tone. Einstein spoke in German and Ortega translated. He emphasized that in reality he was more of a traditionalist than an innovator. In particular, relativity had not changed anything with regard to Maxwell's theory of electromagnetism. It had just reconciled facts that were not reconcilable by using the traditional methods. This was clearly not just modesty on Einstein's part, but his epistemological conviction and probably also constituted an attempt to free himself from the overcharged political and philosophical connotations with which his scientific 
achievements were associated in the Spanish context. In conclusion, the three weeks Einstein spent in Spain probably contributed significantly to changing the public view of science. In addition, the intellectual elite became more favorable to pure science as part of culture and began to rethink their entrenched perspectives on the relation between tradition and modernity.

\section{Einstein in South America ${ }^{7}$}

In 1925, only two years after his Spanish experience, Einstein undertook another trip to the Spanish and Portuguese speaking world, to South America, a trip that lasted an entire three months. At the invitation of Robert Millikan, Einstein had the option to spend some time at Caltech in California, but chose to visit Latin America instead. He was curious to discover a new world and, probably encouraged by his previous travel experiences, was eager to bring the message of science to remote parts of the world. It was the University of Buenos Aires that first took the initiative to invite Einstein, but the invitation was only accepted after the Hebrew Association in Buenos Aires had turned to Einstein's wife Elsa for help. The Hebrew Association partly funded the trip and also established contact with the universities of Montevideo and Rio de Janeiro. Part of Einstein's motivation was to unify the dispersed Jewish community and, in particular, to help establish the Hebrew University in Jerusalem by building up an international support network around it. But he also wanted to use the worldwide enthusiasm for his scientific achievements to overcome ruptures caused by the war and to strengthen peaceful international cooperation. Einstein embarked on his trip with great expectations, but was soon disappointed by the difficulties in getting any substantial messages — scientific or political—across the media hype he encountered wherever he went. Even as his ship was crossing the Rio de La Plata in the middle of the night, a horde of journalists and photographers invaded his cabin for an interview.

The day before Einstein arrived in Argentina, a newspaper published an article of his in which he praised the cultural unity of Europe and criticized narrow-minded patriotism. As a result, the Argentinian-German cultural institute, which had co-organized the trip, refused to take part in the planned events. But the community of German diplomats, émigrés, and descendants also used the occasion to display their national pride, seeking for instance to offset the influence of French culture and science. In his travel diary Einstein noted: "A funny lot, the Germans. I am to them a putrid flower that they keep putting back in their buttonhole."

\footnotetext{
${ }^{7}$ The following is based on (Silva da Silva 2005; Tolmasquim 2005, 2012).

${ }^{8}$ Einstein's travel journal to Argentina, Uruguay, and Brazil. EA 29-133.
} 


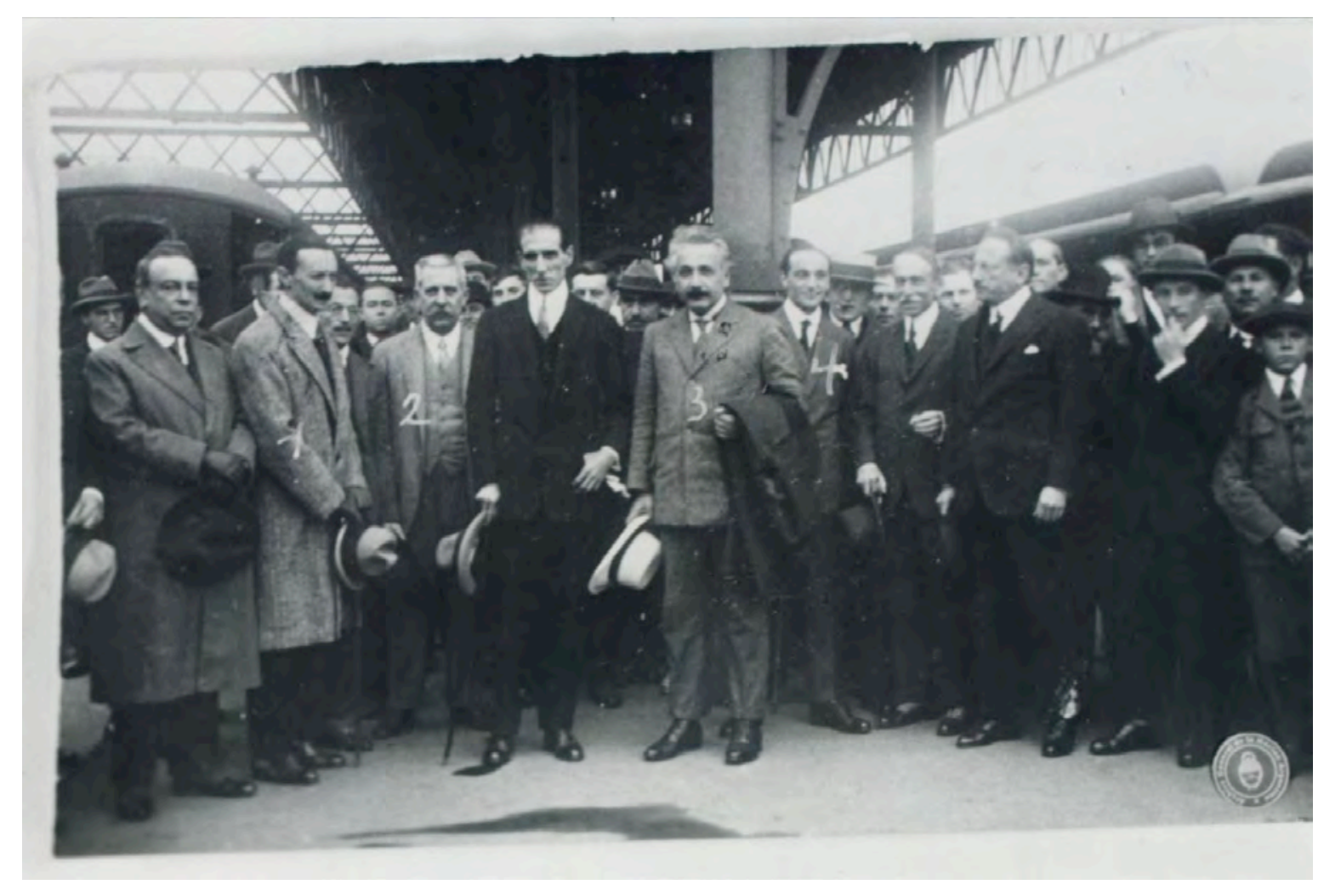

Figure 14: Einstein arriving in Cordoba, Argentina, 1925.

In Argentina, where he stayed for a month, Einstein gave a series of eight lectures on relativity which were written up and published in the newspaper La Nación and later in the journal Revista de Filosofia. He also gave a lecture on "Positivism and idealism: geometry and the finite and unbounded space of the general theory." The title suggests that Einstein at the time did not yet consider general relativity to be part of empirically based astrophysics, but rather part of a philosophically guided mathematical theory of space and time. The turning point would only come with Hubble's discovery at the end of the decade of the redshift of distant galaxies, which was eventually explained by an expanding universe. In Rio, Einstein wrote an article on the state of the theory of light in which he discussed current theoretical and experimental issues of the new quantum theory, which was in the making precisely at this time. He referred to a new proposal by Bohr, Kramers, and Slater and to the experimental work of Bothe and Geiger, which turned out to confirm his theory of light quanta .

As the historian Alfredo Tolmasquim has shown (2012), the reactions to Einstein's relativity theories in South America were shaped by the deep influence that French science and philosophy had asserted on local scientific institutions and also on the local "image of science," to use a term coined by Yehuda Elkana (1981), for shared views on the societal role of science. Einstein in fact gave his lectures in French and the discussions on his theory, in particular in Brazil, were colored by the strong influence that Auguste Comte's 
positivism had gained on the local image of knowledge. Accordingly, science was praised - again in contrast to views prevailing in the imperial era — as being useful, practical, and closely aligned with real life. Against this background, the new relativity theories seemed detached from reality and without immediate practical relevance. The discussions about Einstein's relativity thus evolved into discussions on the societal role of basic science primarily pursued for the gain of knowledge, a point that Einstein continuously stressed in his lectures. Only later in the 1930s did relativity theory become part of the university curriculum in South American universities. It is all the more it is remarkable to note that relativity theory was taught from 1929 at a college in Rio de Janeiro, the Colegio Pedro II.

\section{Leopold Infeld and The Evolution of Physics}

Einstein's early readings later inspired him to engage himself with popular science writing. The best-known example is certainly his joint book with Leopold Infeld: The Evolution of Physics I (1938). But compared with Einstein's monumental scientific writings, and even with his occasional philosophical remarks, this work has not been taken very seriously. We are fascinated by Einstein's original and provocative remarks about the childlike questions he dared to ask about the venerable work of the masters of classical physics, thus revealing their weaknesses as in the story of the Emperor's new clothes. But we have little digested this lesson because, in contrast to Einstein who was not too proud to answer the numerous letters he received from children (Calaprice 2002), we tend to accept that there is a gulf between the experts and the public at large. But could it be that when reconsidered without such blinders, The Evolution of Physics could teach us what Einstein's scattered remarks on philosophy and history of science could not: how he himself conceived of science as a human activity that not only provided specialist insights, but also the same kind of orientation knowledge which he himself had the occasion to enjoy in the literature of his youth and which inspired his own creativity?

At first sight, this seems rather unlikely. After all, The Evolution of Physics covers the entire evolution of physical thinking in one small volume, from intuitive knowledge to quantum physics. This is in stark contrast to the prevailing methodology in the history of science. Here, the emphasis is on strongly contextualized microhistories or more general histories of ideas for which, however, taxonomies and classifications are the main organizational principle. One of the reasons for this limitation is simply the professionalization of the history of science as a historical discipline. This requires the carefully treatment of all relevant sources and possible influences, thus driving an ever increasing specialization. Another reason for the dominance of microhistories is the loss of faith in the grand narratives of progress inherited from the nineteenth century, which suggest that science proceeds along a more or less direct path from superstition and myth to empirical truth. 

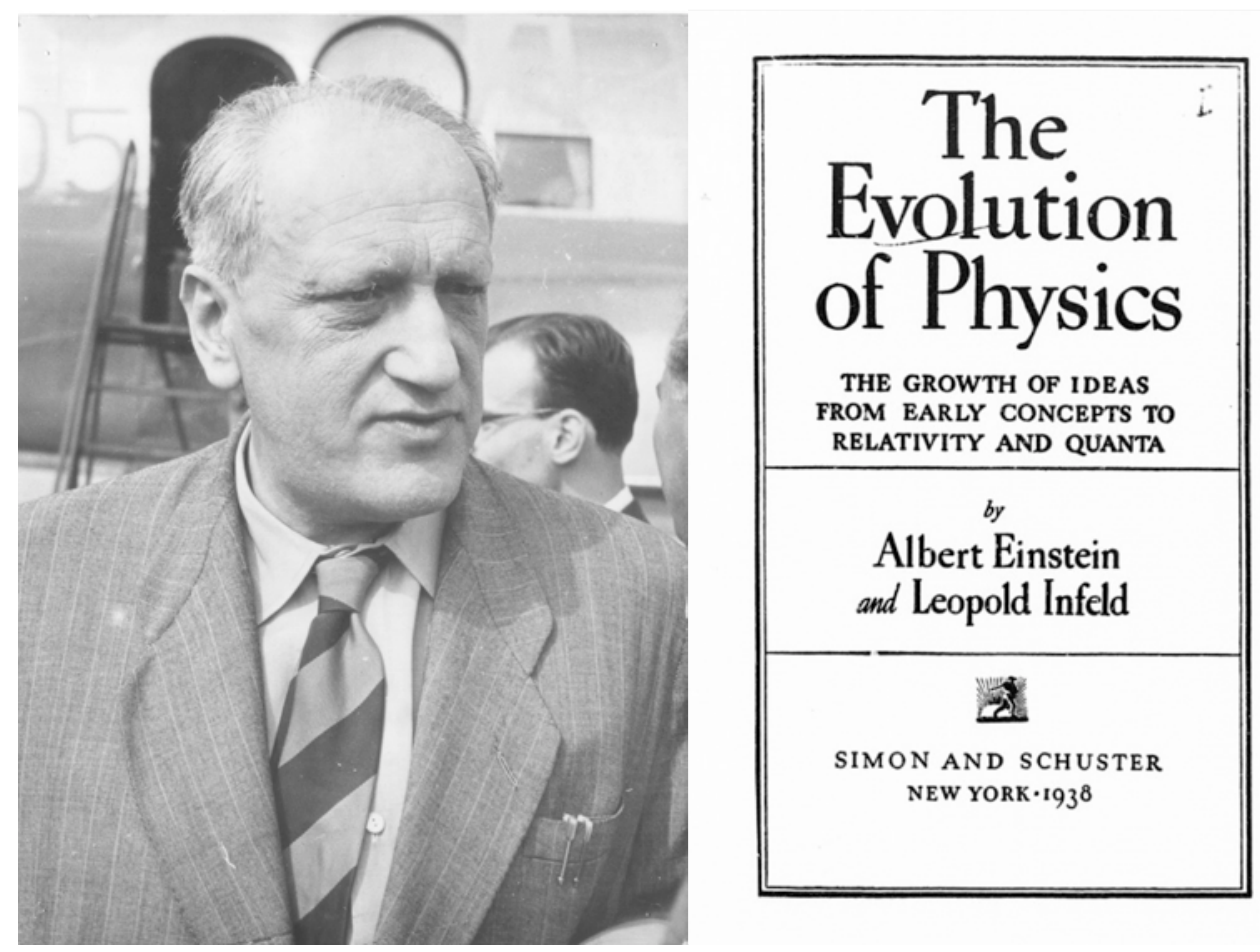

Figures 15: Leopold Infeld and (right) the title page of The Evolution of Physics.

It is true that context in the sense of the modern history of science, that is, the role of personal, cultural, and political constellations, or the conditions for science determined by its material culture, is largely absent from Einstein and Infeld's account. Nevertheless, it does not represent a traditional account of progress or simply a history of great discoveries. From his own experience of rethinking the categories of classical physics, Einstein is instead very much aware of the constructive character and hence the deep historicity of the conceptual framework of physics. Einstein and Infeld therefore avoid a simplistic interpretation of the interplay between theory and experience. The quest of science is instead compared to a detective story that takes into account the most diverse kinds of evidence. According to Einstein and Infeld, the history of science does not unfold as a string of great discoveries more or less in isolation of each other. It is rather an evolutionary process involving the intuitive experiences of everyday physics and a limited number of basic mental models and the questions these suggest. The elaboration of their consequences may lead to difficulties that necessitate a reorganization of the accumulated physical knowledge.

Science thus emerges as mankind's most exciting adventure. The stress on its accessibility and its open-endedness is all-pervasive and implicitly invites the reader to join in. In hindsight, erroneous ideas such as the conception of a mechanical ether as a carrier of light waves are not simply discarded as deviations from the right path, but instead regarded as intellectual challenges that had to be addressed before they could be replaced by the ideas of modern science. From this perspective, exploring the limits of the mechanistic world 
picture becomes the crucial intellectual process and the presupposition to resolve it. Philosophical reflections are rarely discussed explicitly, but still hold their place in this evolutionary picture of the development of physical knowledge as important aspects of the landscape in which they unfold.

In other words, the evolutionary perspective of Einstein and Infeld, in which contingency and rigor or creativity and realism do not exclude each other, promises an alternative to the unsatisfactory choice between the traditional myth of relentless progress and the postmodern deconstruction of the scientific endeavor and its dissection into chance encounters with epistemic objects generating unpredictable outcomes. Such an understanding of science is thus of utmost relevance to the present. If we take it as a suggestion to develop orientation knowledge, it offers guidance in mastering the complex interactions at the boundaries of different disciplines, in evaluating the potential of the new media for a reorganization of scientific knowledge, or in building bridges between the natural sciences and the humanities, and between globalized and local knowledge. Such a cosmopolitan understanding of science could thus persuade a wider public - as Einstein himself did on the basis of his own experience as a self-reflective actor in scientific revolutions - that there is more than just an alternative between a blind belief in progress and an equally blind skepticism concerning the ever-increasing power of science. Einstein's example as a missionary of science may thus open up new channels of science communication that are not just one way streets, but that offer chances of informed democratic participation in dealing with the adventure of science and the challenges it poses.

With the Nazis rising to power in Germany in 1933 and later with the Second World War everything changed. Hopes that the progress of science and technology would help to rebuild a peaceful world were dashed. Yet Einstein remained convinced that science could contribute to a more rational world order and continued to act as its missionary. By way of conclusion, I will relate the encounter that took place between Einstein and Infeld around 1936 and 1937. Infeld, a young Polish émigré had arrived in Princeton to work with Einstein on fundamental problems of general relativity. But the biggest problem was that he had no position and no hopes of finding one. Then an idea struck the young physicist: "What about writing a popular book with Einstein?" The moment this occurred to him, he knew it would solve his financial problems. A book written with Einstein could not fail completely. But should he approach Einstein? How dare he ask him to divert time from his vital scientific concerns? He devised a speech to convince Einstein of this enterprise during their next encounter, concocting arguments such as: "Hitler would be impossible in a country with a high level of scientific popularization." But when he actually met up with Einstein, Infeld could barely open his mouth: "It is difficult to explain ... I hope you won't misunderstand me." He gave up. Einstein looked on in utter astonishment and waited for the rest of the speech. Then he said: "For goodness sake, out with it. I am beginning to get really interested." Then Infeld began to explain his idea and ended with the remark: "The 
greatest men of science wrote popular books, books still regarded as classics. Faraday's popular lectures, Maxwell's Matter and Motion, the popular writings of Helmholtz and Boltzmann still make exciting reading." Einstein looked silently at first, stroking his moustache with his finger. Then he said quietly: "This is not at all a stupid idea. Not stupid at all." Then he stretched out his hand and said to Infeld: "We shall do it" (Infeld 1969). Thus, the famous popular book Evolution of Physics was born, keeping alive Einstein's role as a cosmopolitan missionary of science forever.

\section{References}

Bernstein, Aaron. 1897. Naturwissenschaftliche Volksbücher. 21 Parts in 4 Vols. Berlin: Dümmlers Verlagsbuchhandlung. (Online via ECHO at http://echo.mpiwgberlin.mpg.de/MPIWG:1RUQG5RM.)

Buchwald, Diana K., Jürgen Renn, and Robert Schlögl. 2013. A Note on Einstein's Scratch Notebook of 1910-1913. In Ad Maas and Henriette Schatz (eds.), Physics as a Calling, Science for Society: Studies in Honour of A.J. Kox. Leiden. Leiden University Press.

Calaprice, Alice (ed.). 2002. Dear Professor Einstein: Albert Einstein's Letters to and from Children. Amherst, NY: Prometheus Books.

Silva da Silva, Circe Mary. 2005. The Theory of Relativity in Brazil: Reception, Opposition and Public Interest. In (Renn 2005b, 294-297).

Einstein, Albert. 1987-2009. The Collected Papers of Albert Einstein. Princeton, N.J.: Princeton University Press.

. 1992. Autobiographical Notes: A Centennial Edition. Translated and edited by Paul Arthur Schilpp. La Salle, Ill.: Open Court.

1993. The Collected Papers of Albert Einstein. Vol. 3: The Swiss Years: Writings, 1909 1911. Edited by Martin J. Klein; A. J. Kox; Jürgen Renn. Princeton, N.J.: Princeton University Press.

1995. The Collected Papers of Albert Einstein. Vol. 5: The Swiss Years:

Correspondence, 1902-1914. Edited by Martin Klein, Anne Kox, Jürgen Renn, Robert

Schulmann and et al. Princeton: Princeton University Press, 1995 (English translation by Anna Beck).

2004. The Collected Papers of Albert Einstein. Vol. 9: The Berlin Years:

Correspondence, January 1919-April 1920. Edited by Diana Kormos Buchwald, Robert

Schulmann, József Illy, Daniel J. Kennefick, and Tilman Sauer. Princeton: Princeton University Press, 2004

2009. The Collected Papers of Albert Einstein. Vol. 12. The Berlin Years:

Correspondence, January-December 1921. Edited by Diana Kormos Buchwald, Ze'ev

Rosenkranz, Tilman Sauer, József Illy, and Virginia Iris Holmes. Princeton: Princeton University Press, 2009.

Einstein, Albert and Max Born. 1969. Albert Einstein Max Born Briefwechsel 191-1955. 
Munich: Nymphenburger Verlagshandlung GmbH.

Einstein, Albert and Leopold Infeld. 1938. The Evolution of Physics: The Growth of Ideas from the Early Concepts to Relativity and Quanta. Cambridge: Cambridge University Press.

Eisenstaedt, Jean. 1989. The Low Water-Mark of General Relativity, 1925-1955. In J. Stachel and Don Howard, eds. Einstein and the History of General Relativity. Proceedings of the 1986 Osgood Hill Conference. Einstein Studies, Vol. 1, Boston : Birkhäuser, 277-292.

Elkana, Y. 1981. A Programmatic Attempt at an Anthropology of Knowledge. In E. Mendelsohn and Y. Elkana (eds.), Sciences and Cultures: Anthropological and Historical Studies of the Sciences, vol. 5, 1-76. Dordrecht: Reidel.

Franck, Philip. 1953. Einstein: His Life and Times. New York: Knopf.

Fölsing, Albrecht. 1997. Albert Einstein: A Biography. New York, NY: Viking.

Glick, Thomas F. 1988. Einstein in Spain: Relativity and the Recovery of Science. Princeton: Princeton Univ. Press.

Gregory, Frederick. 1977. Scientific Materialism in Nineteenth Century Germany. Dordrecht: Reidel.

Infeld, Leopold. 1969. Leben mit Einstein : Kontur einer Erinnerung. Wien: Europa Verlag. Isaacson, Walter. 2007. Einstein: His Life and Universe. New York: Simon \& Schuster.

Neffe, Jürgen. 2005. Einstein: eine Biographie. Reinbek bei Hamburg: Rowohlt.

Ravin, James G. 1997. "Albert Einstein and his Mentor Max Talmey", Documenta Ophtalmologica 94 (1997), 1-17.

Renn, Jürgen, Giuseppe Castagnetti, and Peter Damerow. 1999. Albert Einstein: Alte und Neue Kontexte in Berlin. In J. Kocka (ed.) Die Königlich Preußische Akademie der Wissenschaften zu Berlin im Kaiserreich. Berlin: Akademie Verlag, 333-54.

Renn, Jürgen (ed.). 2005a. Albert Einstein - Chief Engineer of the Universe: Einstein's Life and Work in Context. Weinheim: Wiley-VCH.

2005b. Albert Einstein - Chief Engineer of the Universe: One Hundred Authors for Einstein. Weinheim: Wiley-VCH.

2005c. Albert Einstein - Documents of a Life's Pathway. Weinheim: Wiley-VCH.

Renn, Jürgen. 2005d. Einstein's Invention of Brownian Motion. In J. Renn (ed.) Einsteins Annalen Papers: The Complete Collection 1901-1922. Weinheim: Wiley-VCH, 23-37.

Renn, Jürgen. 2006. Auf den Schultern von Riesen und Zwergen: Einsteins unvollendete Revolution. Weinheim: Wiley-VCH.

Renn, Jürgen, Tilman Sauer, and John Stachel. 1997. The Origin of Gravitational Lensing. A Postscript to Einstein's 1936 Science Paper. Science 275, 5297 (1997): 184-86.

Schulmann, Robert. 2005. Einstein's Swiss Years. In (Renn 2005b, 156-160).

Seelig, Carl. 1956. Albert Einstein: A Documentary Biography. London : London.

Sugimoto, Kenji. 2005. Einstein and Japan. In (Renn 2005b, 284-289).

Tolmasquim, Alfredo Tiomno. 2005. Einstein's Journey to South America. In (Renn 2005b, 291- 
293).

Tolmasquim, Alfredo Tiomno. 2012. Science and Ideology in Einstein's Visit to South America in 1925. In C. Lehner, J. Renn, and M. Schemmel (eds.) Einstein and the Changing Worldviews of Physics. Einstein Studies vol. 12, 117-1333. Boston: Springer.

Wazeck, Milena. 2005. Einstein on the Murder List! The Attacks on Einstein and the Theory of Relativity in 1922. In (Renn 2005b, 222-225).

Wazeck, Milena. 2009. Einsteins Gegner: die öffentliche Kontroverse um die Relativitätstheorie in den 1920er Jahren. Frankfurt/Main: Campus Verlag. [English translation forthcoming in 2013 with Cambridge University Press.] 



\title{
MAX-PLANCK-INSTITUT FÜR WISSENSCHAFTSGESCHICHTE
}

\author{
Max Planck Institute for the History of Science
}

Preprints since 2011 (a full list can be found at our website)

411 Henning Schmidgen \& Urs Schoepflin (eds.) Hans-Jörg Rheinberger : a Bibliography

412 Renate Wahsner \& Horst-Heino v. Borzeszkowski Erkenntnis statt Erbauung: Hegel und das naturwissenschaftliche Denken der Moderne

413 Mirjam Brusius From photographic science to scientific photography: Photographic experiments at the British Museum around 1850

414 Viktor J. Frenkel Professor Friedrich Houtermans - Arbeit, Leben, Schicksal. Biographie eines Physikers des zwanzigsten Jahrhunderts. Herausgegeben und ergänzt von Dieter Hoffmann, unter Mitwirkung von Mary Beer

415 Ilana Löwy (ed.) Microscope Slides - Reassessing a Neglected Historical Ressource

416 André L. Blum, John Michael Krois und Hans-Jörg Rheinberger (Hrsg.) Verkörperungen

417 Pietro Daniel Omodeo Sixteenth Century Professors of Mathematics at the German University of Helmstedt. A Case Study on Renaissance Scholarly Work and Networks

418 Peter Schöttler \& Hans-Jörg Rheinberger (éds.) Marc Bloch et les crises du savoir

419 Albert Presas i Puig (ed.) A Comparative Study of European Nuclear Energy Programs

420 Mathias Grote \& Max Stadler (eds.) Membranes Surfaces Boundaries Interstices in the History of Science, Technology and Culture

421 Frank W. Stahnisch The emergence of Nervennahrung: Nerves, mind and metabolism in the long eighteenth century

422 Pietro Daniel Omodeo, Irina Tupikova Aristotle and Ptolemy on Geocentrism: Diverging Argumentative Strategies and Epistemologies (TOPOI - Towards a Historical Epistemology of Space)

423 Han F. Vermeulen Linguistik und Völkerkunde - der Beitrag der historisch-vergleichenden Linguistik von G.W. Leibniz zur Entstehung der Völkerkunde im 18. Jahrhundert [Leicht erweiterte Fassung des Working Papers No. 133 aus dem MPI for Social Anthropology]

424 Alfred Gierer Mit Schiller gegen den „Egoismus der Vernunft“. Zeitübergreifende Gedanken zur Natur des Menschen

425 Annette Vogt Die Berliner Humboldt-Universität von 1945/1946 bis 1960/1961

426 Klaus Geus, Martin Thiering (eds.) Common Sense Geography and Mental Modelling

427 Renate Wahsner Kann eine moderne Naturphilosophie auf Hegelsche Prinzipien gegründet werden? Spekulatives und naturwissenschaftliches Denken

428 Stefano Bordoni Widening the Scope of Analytical Mechanics Duhem's third pathway to Thermodynamics

429 Pietro Daniel Omodeo Copernicus in the Cultural Debates of the Renaissance: Reception, Legacy, Transformation [Part | \& II]

430 Mark Geller \& Klaus Geus (eds.) Productive Errors: Scientific Concepts in Antiquity (TOPOI - Dahlem Seminar for the History of Ancient Sciences)

431 Klaus Gottstein The Amaldi Conferences. Their Past and Their Potential Future

432 Mikuláš Teich The Scientific Revolution Revisited 
433 Lorraine Daston \& Jürgen Renn (Hrsg.) Festkolloquium für Hans-Jörg Rheinberger Beiträge zum Symposium am 24. 1.2011 im Max-Planck-Institut für Wissenschaftsgeschichte

434 Conference Epistemology and History. From Bachelard and Canguilhem to Today's History of Science

435 Jens Høyrup Sanskrit-Prakrit interaction in elementary mathematics as reflected in Arabic and Italian formulations of the rule of three - and something more on the rule elsewhere

436 Jens Høyrup A hypothetical history of Old Babylonian mathematics: places, passages, stages, development

437 Jürgen Renn Schrödinger and the Genesis of Wave Mechanics

438 Pietro Daniel Omodeo L'iter europeo del matematico e medico scozzese Duncan Liddel

439 Irina Tupikova \& Klaus Geus The Circumference of the Earth and Ptolemy's World Map

440 Pietro Daniel Omodeo und Jürgen Renn Das Prinzip Kontingenz in der Naturwissenschaft der Renaissance

441 Horst Kant und Jürgen Renn Eine utopische Episode - Carl Friedrich von Weizsäcker in den Netzwerken der Max-Planck-Gesellschaft

442 William G. Boltz and Matthias Schemmel The Language of 'Knowledge' and 'Space' in the Later Mohist Canon (TOPOI - Towards a Historical Epistemology of Space)

443 Stefano Bordoni Looking for a Rational Thermodynamics in the late XIX century

444 Sonja Brentjes and Jürgen Renn The Arabic Transmission of Knowledge on the Balance

445 Horst Nowacki Archimedes and Ship Design

446 Matthias Schemmel Elements of a Historical Epistemology of Space (TOPOI - Towards a Historical Epistemology of Space)

447 Martin Thiering and Wulf Schiefenhövel Spatial Concepts in Non-Literate Societies: Language and Practice in Eipo and Dene Chipewyan (TOPOI - Towards a Historical Epistemology of Space) 